\title{
ANALISIS TINGKAT KESEHATAN LEMBAGA PERKREDITAN DESA (LPD) DESA PAKRAMAN GEGELANG KECAMATAN MANGGIS KABUPATEN KARANGASEM
}

\author{
${ }^{1}$ Putri Anggreni ${ }^{2}$ Putu Ari Mulyani ${ }^{3}$ Ni Luh Sri Parwati \\ ${ }^{1}$ Program Manajemen, Fakultas Ekonomi, Universitas Mahendradatta \\ Jl. Ken Arok No 12, Peguyangan Denpasar Utara, Bali 80115 \\ ${ }^{2}$ Program Manajemen, Fakultas Ekonomi, Universitas Mahendardatta \\ Jl. Ken Arok No 12, Peguyangan Denpasar Utara, Bali 80115 \\ ${ }^{3}$ Program Manajemen, Fakultas Ekonomi, Universitas Mahendardatta \\ Jl. Ken Arok No 12, Peguyangan Denpasar Utara, Bali 80115 \\ Email : ${ }^{1}$ gekcay@gmail.com, ${ }^{2}$ arimulyani75@yahoo.com
}

\begin{abstract}
Abstrak - Lembaga Perkerditan Desa ( LPD ) merupakan Lembaga keuangan non-bank yang ada disetiap Desa Pakraman yang ada di Propinsi Bali. Tujuan melakukan Peneliti ini adalah untuk mengetahui apakah Lembaga Perkereditan Desa Pakraman Gegelang, Kecamatan Manggis Kabupaten Karangasem dapat mencapai predikat sehat atau tidak dengan menggunakan pedoman atau acuan Peraturan Daerah Provinsi Bali No.4 Tahun 2012 tentang perubahan kedua atas Peraturan Daerah Provinsi Bali No.8 tahun 2002. Penelitian ini menggunakan metode deskriktif karena berusaha memecahkan masalah yang ada pada saat ini, Teknik pengumpulan data yang digunakan observasi, dokumentasi, dan wawancara. Metode dokumentasi yang dipergunakan dalam penelitian ini menggunakan buku - buku, peraturan - peraturan, dan dokumen lain

Berdasarkan Hasil Analisis maka hasil penelitian dapat disimpulkan bahwa mengacu pada Peraturan Daerah Provinsi Bali No.4 Tahun 2012. Tentang Petunjuk Penilaian Kesehatan Lembaga Perkreditan Desa (LPD) kondisi tingkat Kesehatan pada Lembaga Perkreditan Desa Pakraman Gegelang dapat Predikat "Sehat" dengan skor perolehan 98,6. Berdasarkan hasil penelitian, maka saran dapat diberikan kepada pengurus Lembaga Perkereditan Desa (LPD) Desa Pakraman Gegelang, adalah LPD mengelola aktiva produktif secara optimal dan mengalokasikan aktiva produktif untuk kegiatan atau usaha - usaha yang dapat menambah laba atau SHU, misalnya pada bank dan LPD lain. LPD juga harus mampu melihat peluang pasar yang ada dalam penyaluran kredit, tidak hanya pada salah satu sektor saja. Selain itu perlu diadakan penjadwalan pembayaran utang kepada pihak lain diiringi dengan dana yang tersedia. Dengan cara ini diharapkan bisa mencegah terjadinya likuiditas
\end{abstract}

Kata kunci: Analisis Kesehatan Lembaga Perkreditan Desa.

Abstract - The Village Credit Institutions (LPD) is one of the financial institutions that are included in the category of non-bank financial institutions in every Pakraman village in the province of Bali. The purpose of this Researcher is to find out whether the Village Institute of Pakraman Gegelang, Manggis District, 
Karangasem Regency can achieve a healthy predicate or not by using guidelines or references in the Provincial Regulation of Bali Province No.4 of 2012 concerning the second amendment to the Provincial Regulation of Bali Province No.8 years 2002. This study uses descriptive methods because it tries to solve existing problems, data collection techniques used are observation, documentation, and interviews. The documentation method used in this study uses books, regulations, and other documents such as: Financial Reports and the Work Plan of the Pakraman Gegelang Village Credit Institution. The data analysis technique used is the analysis of financial ratios according toln the Bali Provincial Regulation No.4 Year 2012.

Based on the results of the analysis, the results of the study can be concluded that referring to the Bali Provincial Regulation No.4 of 2012. Regarding the Health Assessment Guidelines for Village Credit Institutions (LPD), the level of health at the Credit Institute in the Pakraman Gegelang Village can be rated "Healthy" with a score of 98, 6. Based on the results of the study, the advice can be given to the administrators of the Village Credit Institutions (LPD) Desa Pakraman Gegelang, is the LPD optimally manage productive assets and allocate productive assets to activities or businesses that can increase profits or SHU, for example at banks and other LPDs . LPDs must also be able to see the market opportunities that exist in lending, not only in one sector. In addition, it is necessary to schedule debt payments to other parties accompanied by available funds. In this way it is expected to prevent liquidity.

\section{Keywords : The health of Village Credit Institutions}

\section{PENDAHULUAN}

Perkembangan dunia usaha khususnya di Indonesia berkembang dengan sangat pesatnya. Hal tersebut tidak terlepas dari perkembangan arus globalisasi sehingga menuntut untuk selalu melakukan inovasi. Berbagai perusahaan mulai bermunculan baik itu yang dikelola oleh instansi pemerintah yang berbentuk Badan Usaha Milik Negara/ Daerah ( BUMN/ D ) maupun pihak swasta ( perorangan maupun koperasi ).

Dengan berkembangnya perekonomian bangsa Indonesia, yang diikuti pesatnya perkembangan suatu sistem. Kesehatan atau kondisi keuangan dan non keuangan bank merupakan kepentingan semua pihak terkait, baik pemilik, pengelola lembaga keuangan di Indonesia antara lain ditandai dengan banyaknya bank - bank yang bermunculan, maka sangat diperlukan suatu pengawasan terhadap bank - bank tersebut untuk mengetahui bagaimana keadaan keuangan serta kegiatan usaha masing - masing bank.

Kebijakan perbankan yang dikeluarkan dan dilaksanakan oleh Bank Indonesia sebagai bank sentral pada dasarnya ditujukan untuk menciptakan dan memelihara kesehatan keuangan, baik secara individu maupun perbankan sebagai (Manajemen) bank, Masyarakat pengguna jasa bank (nasabah) serta bank Indonesia selaku otoritas pengawasan bank dan pihak lainya. 
Jurnal Satyagraha

Vol. 03, No. 02, Agustus 2020 - Januari 2021

ISSN : 2620-6358

http://ejournal.universitasmahendradatta.ac.id/index.php/satyagraha

Salah satu Lembaga keuangan yang termasuk katagori Lembaga keuangan non-bank yang menjalankan fungsi intermediari keuangan adalah Lembaga perkereditan Desa (LPD) dalam kegiatanya mengelola dana masyarakat dalam bentuk Tabungan Deposito untuk disalurkan berupa kredit kepada masyarakat.

Dalam melaksanakan kemandirian keuangan desa adat di Propinsi Bali, maka pada tahun 1984 Pemerintah Provinsi Bali mendirikan Lembaga Perkreditan Desa (LPD). Berdasarkan Surat Keputusan Gubernur Kepala Daerah Tingkat I Bali No. 972 Tahun 1984 tertanggal 1 November 1984 yang dilanjutkan kembali dengan peraturan Daerah Provinsi Bali No. 2 Tahun 1988 tertanggal 27 Januari 1988. Guna lebih memantapkan kelembagaan LPD di seluruh Bali, maka Pemerintah Daerah Provinsi Bali kembali mengeluarkan Peraturan Daerah (PERDA) Provinsi Bali No.8 Tahun 2002 tentang Lembaga Perkreditan Desa disertai Keputusan Gubernur yang mengatur pendirian, lapangan usaha, modal, organisasi, rencana kerja dan anggaran, pelaporan dan pengawasan pembinaan LPD kemudian Pemerintah Daerah Provinsi Bali No.4 Tahun 2012 tentang perubahan kedua atas Peraturan Daerah Provinsi Bali No. 8 tahun 2002 tentang Lembaga Perkreditan Desa. LPD Bali dianggap sebagai LKM paling sukses yang ada di Bali. Lembaga Perkreditan Desa merupakan badan usaha milik desa yang melaksanakan kegiatan usaha di lingkungan desa dan hasilnya dinikmati oleh krama desa setempat.
Lembaga Perkereditan desa (LPD) Pakraman Gegelang dari periode ke periode belum pernah dilakukan penilaian terhadap kinerja dan kesehatan keuangan perusahaan, hal inilah yang menjadikan peneliti tertarik untuk meneliti lebih jauh tentang kondisi kauangan dan tingkat kesehatan keuangan pada Lembaga Perkereditan Desa (LPD) Pakraman Gegelang mengacu pada Praturan Daerah Provinsi Bali Nomor 8 Tahun 2002 Tentang Lembaga Perkereditan Desa sebagai telah diubah beberapa kali terakhir dengan Peraturan Daerah Provinsi Bali Nomor 4 tahun 2012 tentang perubahan kedua atas Peraturan Daerah Provinsi Bali Nomor 8 Tahun 2002 tentang Lembaga Perkereditan Desa mengenai Tata Cara Penilaian Kesehatan (LPD). Penilaian Kesehatan Lembaga Perkereditan Desa (LPD) di gunakan untuk mengetahui seberapa sehatnya Lembaga Perkereditan Desa (LPD) dalam melaksanakan usahanya. Agar penilaian tersebut didapatkan hasil yang valid serta dapat bermanfaat bagi pengambil keputusan untuk bisa melanjutkan usahanya untuk lebih maju dan berkembang serta tujuan dari Lembaga Perkereditan Desa (LPD) bisa tersebut tercapai dengan baik. Oleh karena itu, dalam penelitian ini ingin mengetahui bagaimana tingkat kesehatan pada Lembaga Perkereditan Desa (LPD) tahun buku 2019 Lembaga Perkereditan Desa (LPD) Pakraman Gegelang Kecamatan Manggis Kabupaten Karangasem.

Berdasarkan latar belakang tersebut penulis menilai Lembaga Perkereditan Desa (LPD) Pakraman Gegelang, Kecamatan Manggis, Kabaupaten 


\section{Jurnal Satyagraha}

Vol. 03, No. 02, Agustus 2020 - Januari 2021

ISSN : 2620-6358

http://ejournal.universitasmahendradatta.ac.id/index.php/satyagraha

Karangasem layak dan menarik untuk

\section{METODE}

Rancanagan penelitian diawali dari identifikasi masalah untuk selanjutnya merumuskan masalah agar bisa ditentukan data - data yang diperlukan, untuk selanjutnya di lakukan analisis. Hasil analisis kemudian dilakukan pembahasan, yang nantinya menghasilkan kesimpulan dan saran saran dari penelitian.

Populasi adalah wilayah generalisasi yang terdiri dari objek atau subjek yang menjadi kuantitas dan karakteristik tertentu yang ditetapkan oleh peneliti untuk dipelajari dan kemudian ditarik kesimpulanya ( Sugiyono, 2006 ). Jadi , populasi merupakan objek dan subjek yang berada pada suatu wilayah dan memenuhi syarat - syarat tertentu yang mempunyai kaitan dengan masalah yang diteliti. Populasi yang digunakan dalam penelitian ini adalah seluruh laporan keungan LPD Desa Pekraman Gegelang.

Sampel penelitian merupakan sebagian dari elemen - elemen populasi ( Indiantoro dan Supomo, 2002 ). Pemilihan elemen populasi sebagai sampel dalam penelitian ini didasrkan pada tujuan dan masalah penelitian, sehingga tujuan penelitian ini dapat tercapai. Sampel pada penelitian ini yaitu laporan keuangan khususnya tentang Neraca pada LPD Desa Pekraman Gegelang Tahun 2019.

Data yang digunakan adalah Data kuantitatif, yaitu data yang berupa angka - angka seperti laporan keuangan, meliputi laporan laba rugi dan neraca Lembaga Perkereditan Desa (LPD) Desa Pakraman Gegelang tahun di teliti.

2019. Data kualitatif, data yang tidak berupa angka - angka yang sifatnya sebagai penunjang dalam pembahasan misalnya sejarah berdirinya dan struktur organisasi LPD.

Sumber data Data Primer, yaitu data yang dicatat dan diamati langsung dari obyek penelitian yaitu dari Lembaga Perkereditan Desa (LPD) Desa Pakraman Gegelang seperti setruktur organisasi dan data sekunder yang sudah diolah dan disajikan untuk pihak lain yang meliputi gambaran umum LPD sejarah dan laporan keuangan.

Teknik analisiss data yang digunakan dalam penelitian ini untuk menganalisis data - data yang tersedia berdasarkan Perda No. 8 tahun 2002 sebagai berikut : Analisis kuantitatif : Aspek Permodalan / Kecukupan Modal (CAR), Aspek aktiva produktif, Aspek manajemen, Aspek

Earning/Rentabilitas, Aspek likuiditas, 
HASIL DAN PEMBAHASAN

LPD Desa Pakraman Desa

Gegelang beroprasi sejak tanggal

8 Nopember 1991 dengan berpedoman pada Keputusan Gubernur Kepala Daerah Tingkat 1 bali Nomor : 717 Tahun 1991. LPD Desa Pakraman Gegelang memiliki modal awal sebesar Rp. 5.000.00,00 (Lima Juta Rupiah). Yang berasal dari Anggaran Pendapatan Belanja daerah Pemerintah Daerah Tingkat I Bali. Pada akhir tahun 2019 modal dasar/ modal donasi LPD Desa Pakraman Gegelang sebesar Rp. 33.665.400,00 ( tiga puluh tiga juta enma ratus enam puluh lima ribu empat ratus rupiah ).

Pada awalnya LPD Desa Pakraman Gegelang menempati Kantor yang berlokasi di Dusun Gegelang Desa Gegelang Kecamatan Manggis Kabupaten Karangasem yang sangat sederhana serta peralatan seadanya. LPD Desa Pakraman Gegelang didukung oleh 6 ( enam ) Banjar yang ada diwilayah Desa pakraman Desa Gegelang dengan tiga orang pengurus yang langsung merangkap sebagai karyawan. Berkat perjuangan prajuru dan pengurus Lembaga Perkereditan Desa meyakinkan masyarakat dan memperomosikan Lembaga Perkreditan Desa ke Banjar melalui semangat pengabdian dukungan dan partisipasi masyarakat LPD Desa Pakraman Gegelang mengalami kemajuan dan perkembangan. Hal ini tidak terlepas dari kerjasama yang baik antar pengurus Desa, Kelihan Banjar, Pengurus Lembaga Perkreditan Desa, dan karma Desa Pakraman Gegelang, Pada tahun 2016 LPD
Desa Pakraman Gegelang berhasil membangunan kantor yang baru dengan bangunan 2 lantai dengan luasan kurang lebih $60 \mathrm{~m}^{2}$.

Analisis Aspek Penilaian Kesehatan

Aspek Permodalan

Dari data terdapat rasio Modal LPD terhadap ATMR adalah 13,53\% ada kenaikan 1,53\% dari pemenuhan kecukupan modal yaitu $12 \%$, sehingga dengan kecukupan modal sebesar $12 \%$ maka diberi nilai 81 , untuk mendapatkan nilai CAR maka 81 ditambahkan dengan rasio kas $13,53 \%$ dikurangi 12 dibagi 0,1 memperoleh nilai CAR 96,30. Dengan nilai CAR 96,33 dikalikan dengan bobot penalaian 25\% didapatkan nilai Kesehatan CAR sebesar 24,1.

\section{Aktiva Produktif}

Persentase rasio Aktiva produktif yang di klasifikasikan terhadap Aktiva produktif adalah sebesar $0,90 \%$ ada penurunan $6,90 \%$ dari standar maksimum rasio $7,80 \%$ maka nilai KAP memperoleh nilai 127,33 maka diberi batasan nilai maksimum 100 dikalikan dengan bobot 25\% sehingga memperoleh nilai 25. Karena persentase rasio CPRR adalah 174,90\% terjadi kenaikan sebesar 93,90\% dari standar rasio minimal $81 \%$ maka nilai CPRR adalah 174,90 maka diberi batasan nilai maksimum 100 dikalikan dengan bobot $10 \%$ sehingga memperoleh 10.

\section{Aspek Manajemen}

Dari hasil wawancara ditunjukan pada karyawan/Kepala LPD Desa Pakraman Gegelang yang meliputi lima komponen yaitu manajemen Strategi/sasaran, 
struktur/klembagaan, manajemen sistem, manajemen kepemimpinan, manajemen resiko, manajemen resiko likuiditas, manajemen resiko kredit, manajemen resiko oprasional, manajemen resiko hukum, dan manajemen resiko pemilik pengurus. Total nilai untuk aspek manajemen adalah 95, maka dikalikan dengan bobot Kesehatan LPD 10\% sehingga memperoleh nilai 9,5.

\section{Aspek Rentabilitas}

Return On Asset (ROA) adalah perbandingan laba tahun buku berjalan terhadap total rata - rata asset adalah sebesar 3,09\% berada diatas standar rasio Kesehatan LPD sebesar $1,065 \%$ dari standar rasio yaitu $2,025 \%$ maka nilainya adalah 123,60 karena Batasan nilai maksimum 100, maka 100 dikalikan dengan bobot $10 \%$ sehingga nilainya 10.

Biaya Operasional Pendapatan (BOPO) Rasio BOPO yaitu Biaya Oprasional Terhadap Pendapatan Oprasional adalah $67,27 \%$ ada penurunan $12,48 \%$ dari standar maksimal Rasio yang ditetapkan sebesar 79,75\% maka nilai Rasio BOPO adalah 130,92 karena batas maksimum 100, maka 100 dikalikan dengan bobot $10 \%$ sehingga memperoleh nilai 10 .

Rasio Likuiditas, karena rasio alat likuiditas terhadap Hutang Lancar adalah $17,50 \%$ ada kenaikan $13,45 \%$ dari standar rasio minimal yaitu $4,05 \%$ dengan demikian maka setiap kenaiakan $0,05 \%$ dari nilai ditambah 1 dengan nilai alat likuid sebesar 350,00 namun batas maksimum adalah 100, maka 100 dikalikan dengan bobot 5\% sehingga memperoleh nilai 5 .
Loaren Deposit Ratio (LDR) ,karena rasio pinjaman yang diberikan terhadap dana yang diterima adalah $75,84 \%$ ada penurunan $18,91 \%$ dari standar rasio maksimal yaitu 94,75\% sesuai dengan nilai kredit faktor untuk setiap penurunan $1 \%$ dari rasio $115 \%$ nilai kreditnya di tambah 4 . Nilai LDR sebesar 156,64 dengan Batasan mmaksimum 100, maka 100 dikalikan dengan bobot 5\% sehingga nilainya adalah 5 .

Batas Maksimum Pemberian Kredit (BMPK) Rasio BMPK terhadap modal adalah $0,07 \%$ dikurangi $20 \%$ maka nilainya adalah $-19,3 \%$ atau $0 \%$ atau tidak ada pelanggaran dalam pemberian kredit karena batasan pemberian kredit Rp. 858.666.496,-. Sedangkan pinjaman satu orang / kelompok hanya sebesar Rp. 300.000.000,- sehingga total nilai BMPK adalah 0,00 sebagai pengurangan dari nilai kesehatan LPD.

\section{Penetapan Hasil Analisis} Kesehatan LPD Desa Gegelang Jumlah Skor Hasil Penilaian LPD Desa Pakraman Gegelang adalah 98,6 Berada pada rentang nilai 81 100 , berarti termasuk kriteria sehat.

Dari hasil perhitungan penilaian kesehatan selama tahun 2019 maka jumlah skor keseluruhan dapat dilihat pada tabel diatas kemudian hasil perhitungan skor dibandingkan dengan Penetapan Predikat Kesehatan LPD menurut Peraturan Daerah Provinsi Bali no. 8 Tahun 2002 tentang Lembaga Perkreditan Desa selama tahun 2019 pada Lembaga Perkreditan Desa (LPD Desa Pakraman Gegelang Kecamatan Manggis Kabupaten Karangasem menunjukkan Penilaian 
Tingkat Kesehatan sebesar 98,6 menujukan predikat Sehat.

\section{SIMPULAN DAN SARAN}

Berdasarkan analisis dan pembahasan diatas, maka dapat disimpulkan sebagai berikut :

Dari hasil perhitungan rasio keuangan LPD Desa Pakraman Gegelang Periode 31 Desember 2019 sesuai dengan Penilaian Tingkat Kesehatan didasari atas Peraturan Daerah Provinsi Bali No. 4 Tahun 2012 tentang perubahan kedua atas Peraturan Daerah Provinsi Bali No. 8 Tahun 2002. LPD Desa Pakraman Gegelang berada pada posisi/kriteria sehat.

Berdasarkan kesimpulan diatas saran yang dapat diberikan untuk LPD Desa Pakraman Gegelang diantaranya :

\section{UCAPAN TERIMA KASIH}

Ucapan terima kasih diberikan kepada Universitas Mahendradatta, rekan - rekan Ibu/Bapak dosen di lingkungan Universitas Mahendradatta sehingga karya tulis ini dapat terselesaikan dengan tepat waktu.

\section{DAFTAR PUSTAKA}

Affit, Faisal dan Utjap Supandi. 1984. Menejemen Modal Kerja. Bandung : CV Remaja Karya.

Darminto, Dwi Darminto. 2015. Analisis Laporan Keuangan. Edisi Ketiga. Yogyakarta: UPP STIM YKPN.

Dukat, Erwin. 1999. Alat-Alat Analisis Keuangan. Jakarta:
Lembaga Perkreditan Desa (LPD) hendaknya lebih produktip dalam memberikan pinjaman dilihat dari pemodalan yang ada, namun selalu pada prinsip 5C menetapkan agunan walaupun jumlah pinjaman yang diberikan relative kecil, Lembaha perkreditan desa (LPD) hendaknya perlu menambah aspek permodalan karena cadangan belum mencukupi standar yang ditetapkan, LPD Desa Pakraman Gegelang hendaknya mampu melihat peluang pasar yang ada dalam penyaluran kredit tidak hanya pada salah satu sector saja, Untuk meningkatkan kualitas kinerja LPD perlu ditingkatkan kualitas Sumber daya manusia (SDM) pengelola/karyawan sesuai dengan kebutuhan perusahaan sehingga tercipta manajemen yang selaras untuk berkelanjutan LPD itu sendiri.

PT. Gramedia Pustaka Utama.

Gubernur Bali. 2013. Peraturan Daerah Propensi Bali Nomor 4 Tahun 2012. Denpasar: Setda Provinsi Bali.

Ivancevich, dkk. 2008. Perilaku dan Manajemen Organisasi. Jakarta : Erlangga

J.F, Weston and Brigham E.F. 1980. Managerial Finance. Disitasi Oleh Winardi. Bandung : Alumni Bandung.

Manullang, M. 1991. Pengantar Ekonomi Perusahaan. Yogyakarta: Penerbit Fakultas Ekonomi Universitas Islam Indonesia Manullang, M. 1980. Pokok-Pokok Pembelanjaan Perusahaan, 
Yogyakarta : Yayasan

Badan Penerbit Gajah Mada.

Munawir, S. 1981. Analisa Laporan

Keuangan. Cetakan Kelima.

Yogyakarta : Liberty

Yogyakarta.

Punaji Setyosari. 2010. Metode

Penelitian Pendidikan dan

Pengembangan. Jakarta:

Kencana Prenada Media

Group.

Render, B, \& Heizer, J. 2001.

Prinsip-Prinsip Manajemen

Operasi. Terjemahan Arianto, Jakarta: Salemba Empat.

Robbins dan Judge. 2007. Perilaku

Organisasi, Jilid 2. Jakarta :

Salemba Empat

Saud Husnan. 1985. Menegemen

Keuangan Teori dan

Penerapan (Keputusan

Jangka Pendek). Jilid 2.

Yogyakarta : BPPI

Yogyakarta.

Sawir, Agnes. 2003. Analisis Kinerja

Keuangan dan Perencanaan

Keuangan. Jakarta: PT.

Gramedia Pustaka Utama.

Subagya, P. 2000. Manajemen

Operasi, Edisi Pertama.

UGM Yogyakarta: BPFE.

Surakhmad, Winarno. 1982.

Pengantar Penelitian Ilmiah.

Bandung : Penerbit Tarsito.

Syah, Mahendra Sultan. 2004.

Menejemen Proyek. Jakarta:

PT. Gramedia Pustaka

Utama.
Yamit, Z. 2000. Manajemen

Produksi Dan Operasi,

Ekonisia. Yogyakarta : FE

UII.

Putri Anggreni 